\title{
Correlation between Hemoglobin Concentration and Cardiorespiratory Fitness in Adolescent Sportsmen
}

\author{
Billy Leoprayogo, ${ }^{1}$ Venna, ${ }^{2}$ Ignatio Rika Haryono, ${ }^{3}$ Francisca Tjhay ${ }^{4}$ \\ ${ }^{1}$ School of Medicine and Health Sciences Atma Jaya Catholic University of Indonesia, Indonesia, \\ ${ }^{2}$ Department of Clinical Pathology School of Medicine and Health Sciences Atma Jaya Catholic \\ University of Indonesia, Indonesia, ${ }^{3}$ Department of Physiology School of Medicine and Health \\ Sciences Atma Jaya Catholic University of Indonesia, Indonesia, ${ }^{4}$ Department of Medicine Biology \\ School of Medicine and Health Sciences Atma Jaya Catholic University of Indonesia, Indonesia
}

\section{Abstract}

Background: Sport is a physical activity that increases human body oxygen demand. Hemoglobin has a major role to fulfill the oxygen demand. The ability to fulfill this demand was also seen as cardiorespiratory fitness. Sportsmen have a high cardiorespiratory fitness due to the intensity and frequency of training. This study aimed to explore the effect of hemoglobin concentration on cardiorespiratory fitness of adolescent sportsmen.

Methods: This was a cross-sectional study conducted from October-November 2019. Male badminton and basketball sportsmen aged 15-19 years old in Jakarta and Bogor were recruited $(n=72)$. Hemoglobin concentration was measured with a digital hemoglobinometer. The V02max was estimated with a beep test. FITNESSGRAM $®$ Performance Standard was used for the classification of cardiorespiratory fitness. The hemoglobin concentration and cardiorespiratory fitness were then analyzed (Spearman and Kruskal-Wallis).

Results: There was a correlation between hemoglobin concentration and cardiorespiratory fitness $(\mathrm{p}=0.001)$, although the correlation was weak $(\mathrm{r}=0.38)$. Kruskal-Wallis analysis showed there was a significant mean difference in hemoglobin concentration on cardiorespiratory fitness groups $(\mathrm{p}=0.005)$.

Conclusions: The mean of the hemoglobin concentration in the Healthy Fitness Zone (HFZ) cardiorespiratory group is higher than in the Need Improvement (NI) group and the Need Improvement within Health Risk (NI-HR) group.

Keywords: Adolescent sportsmen, cardiorespiratory fitness, hemoglobin concentration

\section{Introduction}

Sport is a form of physical activity that is planned and structured, involving various movements of many muscle groups which are done repeatedLy. Sports have a good impact on adolescent's bodies such as increased bone density, cognitive development, and also an increase in cardiorespiratory fitness which is expressed by an increase in V02max. ${ }^{1}$ Basketball and badminton are physical activities. ${ }^{2,3}$ Both of these exercises increase the body's oxygen demand because it performs repeated muscle contraction in large quantities for a period of time and both sports require movement from the upper and lower extremities.

Hemoglobin is needed to fulfill this need because of its role as the transporter of the oxygen from the lungs to tissues and muscles throughout the body. ${ }^{4}$ Hemoglobin also acts as a buffer that maintains the $\mathrm{pH}$ of the blood to remain in optimal condition for aerobic metabolism. ${ }^{5}$ Looking at the role of hemoglobin during exercise, hemoglobin concentration also affects the quality of individual cardiorespiratory fitness. The V02max had an increase of about $1 \%$ for each increase in

Correspondence: Francisca Tjhay, Department of Medicine Biology, School of Medicine and Health Sciences Atma Jaya Catholic University of Indonesia, Jl. Pluit Raya No. 2, Penjaringan, Jakarta Utara, Indonesia, E-mail: francisca.tjhay@atmajaya.ac.id 
Table 1 Distribution of Hemoglobin Concentration and Cardiorespiratory Fitness

\begin{tabular}{lccccc}
\hline & & \multicolumn{2}{c}{ Hemoglobin Concentration } & \multirow{2}{*}{ Total } \\
\cline { 3 - 5 } & & Low & Normal & High & \\
\hline Cardiorespiratory & NI-HR & 7 & 15 & 2 & 24 \\
Fitness & NI & 4 & 17 & 3 & 24 \\
& HFZ & - & 19 & 5 & 24 \\
Total & & 11 & 51 & 10 & 72 \\
\hline
\end{tabular}

Note: ${ }^{\mathrm{a}}=$ Hemoglobin concentration for male adolescent; Low $=$ Hb concentration <14 g/dL; Normal=Hb concentration $=14-17.5 \mathrm{~g} / \mathrm{dL}$; High=Hb concentration $>17.5 \mathrm{~g} / \mathrm{dL}$. The cardiorespiratory fitness was grouped into; NI-HR=need Improvement within health risk, $\mathrm{NI}=$ need improvement, $\mathrm{HFZ}=$ healthy fitness zone

Hb concentration by $0.3 \mathrm{~g} / \mathrm{dL}^{6}{ }^{6}$ This shows the effect of $\mathrm{Hb}$ in cardiorespiratory fitness.

This study aimed to explore the correlation between hemoglobin concentration and cardiorespiratory fitness, especially in adolescent sportsmen. Adolescents were targeted to improve their cardiorespiratory fitness by exercising regularly to increase and maintain their physical fitness.

\section{Methods}

This was a cross-sectional study conducted from October-November 2019 among male badminton and basketball players aged 15-19 years old in Jakarta and Bogor. The sampling technique was a snowball sampling until the number of respondents met the sample target. The inclusion criteria were those who were willing to take part in the study after consent and underwent the hemoglobin concentration examination.

In brief, the hemoglobin concentration was measured with a digital hemoglobinometer with an azide-methemoglobin method that has been tested for the validity and reliability using within the run and between day methods. The hemoglobin concentration was then grouped into the following; low concentration with $\mathrm{Hb}<14 \mathrm{~g} / \mathrm{dL}$, normal concentration with $\mathrm{Hb}$ 14-17.5 g/dL, and high concentration with $\mathrm{Hb}$ $>17.5 \mathrm{~g} / \mathrm{dL}$.

Each respondent went through hemoglobin examination before conducting the beep test which was calculated using a quadratic formula model to estimate the $\mathrm{VO}_{2}$ max. Cardiorespiratory fitness was then classified with the FITNESSGRAM ${ }^{\circledR}$ Performance Standard classification based on the estimated V02max. The respondents were then group into cardiorespiratory fitness groups; healthy fitness zone (HFZ), need improvement (NI) group, and need improvement within health risk (NI-HR) group.
The data obtained were then processed using the SPSS program. Data distribution was tested by the Kolmogorov-Smirnov. When data were not normally distributed, the Spearman correlation test was performed and continued with the Kruskal-Wallis hypothesis test.

\section{Results}

In total, there were 77 male sportsmen recruited, consisting of basketball players and badminton players. Due to rejection in the $\mathrm{Hb}$ concentration examination, 5 subjects were excluded, thus, only 72 sportsmen were included for further analysis. The average hemoglobin concentration of these sportsmen was $15.9 \pm 1.6 \mathrm{~g} / \mathrm{dL}$ (range 12.5$18.7 \mathrm{~g} / \mathrm{dL}$ ). There were 11 sportsmen who had low $\mathrm{Hb}$ concentrations, which fall in the cardiorespiratory group of NI-HR $(n=7)$, NI $(n=4)$, but none in the HFZ group. The distribution of hemoglobin concentration among the cardiorespiratory fitness group was shown in Table 1.

A correlation test between hemoglobin concentration and cardiorespiratory fitness had shown a value of $\mathrm{r}=0.38 \quad(\mathrm{p}=0.001)$, suggesting a positive mild correlation between hemoglobin concentration and cardiorespiratory fitness.

Table 2 Mean of Hemoglobin Concentration and Cardiorespiratory in Fitness Group

\begin{tabular}{cc}
\hline $\begin{array}{c}\text { Cardiorespiratory } \\
\text { Fitness }\end{array}$ & $\begin{array}{c}\text { Mean Hb } \\
\text { concentration } \\
\text { (g/dl) }\end{array}$ \\
\hline NI-HR & 15.3 \\
NI & 15.7 \\
HFZ & 16.7
\end{tabular}

Note: NI-HR= need improvement within health risk; NI= need improvement; HFZ= healthy fitness zone 
There was a different mean of hemoglobin concentration on cardiorespiratory fitness groups (Kruskal-Wallis test, $\mathrm{p}=0.005$ ). A post hoc analysis was used after the Kruskal-Wallis test to know which group have different mean hemoglobin concentration. It showed a value of $\mathrm{p}=0.02$ for HFZ and NI group, $\mathrm{p}=0.001$ for HFZ and NI-HR group, and $\mathrm{p}=0.40$ for NI and NI-HR group $(p<0.05)$. These results indicated that the HFZ had a significant difference of mean hemoglobin concentration with both NI and NI-HR groups, but between the NI and NIHR group, no statistical difference was found. The mean hemoglobin concentration of each cardiorespiratory fitness group was shown in Table 2.

\section{Discussion}

Sport is a physical activity which increases the oxygen demand of the human body. There are physiological changes that occur during exercise such as a 1.5 to 2 times increased heart rate than at rest and an increase in respiratory rate from about 16 times/minute up to 60-80 times/minute. ${ }^{7}$ This physiological change is an attempt that our body does to meet the increase in oxygen consumption that occurs from about $250 \mathrm{ml} /$ minute at rest to 3000-5000 ml/minute when exercising. ${ }^{8}$

The oxygen needed by the body to meet the increased demand when doing exercise is delivered by hemoglobin. This study has shown that the average hemoglobin concentration is higher in sportsmen with higher cardiorespiratory fitness. Blood composition changes during and after exercise, and there is an effect of exercise on red blood cells oxygen supply ability. Plasma volume is decreased and hematocrit is increased during exercise. The increase of hematocrit occurs relatively due to the blood plasma volume loss. Blood plasma exits the blood vessels into the extracellular space due to a difference in osmotic pressure caused by muscle metabolites and increased capillary hydrostatic pressure. ${ }^{9}$

Interestingly, another study on the effect of blood donation on cardiorespiratory fitness observed the changes in cardiorespiratory fitness of respondents before and after $450 \mathrm{ml}$ blood donation. Respondents conducted blood tests and beep tests on the first day continued with blood donation on the second day. Second blood test and second beep test on the third day. The study showed that the decline in cardiorespiratory fitness 24 hours after blood donation were generally not visible. However, the group with good cardiorespiratory fitness experienced a significant decline after blood donation. $^{10}$ The parameter of blood that affects cardiorespiratory fitness is the oxygencarrying capacity of the blood which is the role of hemoglobin. The recovery of blood volume after 24 hours of blood donation reaches a volume that was almost similar to the beginning, but the hemoglobin concentration was not returned to the initial concentration due to hemodilution.

This study showed the same results as there were differences in hemoglobin concentration on the HFZ group with other groups as the HFZ group have better cardiorespiratory fitness than the other groups. The relationship of hemoglobin concentration with cardiorespiratory fitness has shown that V02max has the strongest relationship with oxygen-carrying capacity from the blood.

The parameters that play a major role in the carrying capacity of oxygen are hemoglobin concentration, blood volume, and also the total mass of hemoglobin. The parameter which has the strongest relationship to the oxygen-carrying capacity is the total mass of hemoglobin, ${ }^{11}$ suggestings that the correlation in this study is weak. Future research is needed to elucidate the cardiorespiratory fitness and their factors that might improve the quality of physical fitness in adolescent sportsmen.

There are factors affecting hemoglobin concentration in the blood. ${ }^{12}$ This study has managed to control these factors which include sportsmen smoking behavior, previous hematological disorders, history of iron supplementation therapy, and history of living in high-altitude places, however, this study has no data of sportsmen's regular diet to evaluate daily iron intake. ${ }^{13,14}$ The recommended intake for iron is $10.8-18.4 \mathrm{mg} /$ day. ${ }^{15}$ Iron intake highly affects hemoglobin concentration, which may cause false positive on the low hemoglobin concentration in the NI-HR group.

In conclusion, there is a positive correlation between hemoglobin concentration and cardiorespiratory fitness in sportsmen aged 15-19 years old in this study, especially those in the Healthy Fitness Zone. The hemoglobin concentration varies among sportsmen, which the majority of them within the normal range.

Therefore, sports clubs and the sportsmen should aware of how hemoglobin concentration could affect cardiorespiratory fitness and how to improves or maintain the performance of sportsmen in competition, as cardiorespiratory fitness improve endurance and recovery time of physical fitness. 


\section{References}

1. McKinney J, Lithwick DJ, Morrison BN, Nazzari H, Isserow SH, Heilbron B, et al.. The health benefits of physical activity and cardiorespiratory fitness. BC Med J. 2016;58(3):131-7.

2. Silva AM, Santos DA, Matias CN, Minderico CS, Schoeller DA, Sardinha LB. Total energy expenditure assessment in elite junior basketball players: a validation study using doubly labeled water. J Strength Cond Res. 2013;27(7):1920-7.

3. Briggs MA, Cockburn E, Rumbold PLS, Rae G, Stevenson EJ, Russell M. Assessment of energy intake and energy expenditure of male adolescent academy-level soccer players during a competitive week. Nutrients.2015;7(10):8392-401.

4. Longeville S, Stingaciu LR. Hemoglobin diffusion and the dynamics of oxygen capture by red blood cells. Sci Rep. 2017;7(1):10448.

5. Chowdhury A, Dasgupta R, Majumder SK. Changes in hemoglobin-oxygen affinity with shape variations of red blood cells. J Biomed Opt. 2017;22(10):1-9.

6. Otto JM, Montgomery HE, Richards T. Haemoglobin concentration and mass as determinants of exercise performance and of surgical outcome. Extrem Physiol Med. 2013;2(1):33.

7. Savonen KP, Lakka TA, Laukkanen JA, Halonen PM, Rauramaa TH, Salonen JT, et al. Heart rate response during exercise test and cardiovascular mortality in middLeaged men. Eur Heart J. 2006;27(5):582-8.

8. Nicolò A, Girardi M, Bazzucchi I, Felici F, Sacchetti M. Respiratory frequency and tidal volume during exercise: differential control and unbalanced inter dependence. Physiol Rep. 2018;6(21): e13908.

9. Mairbäurl H. Red bloodcells in sports: effects of exercise and training on oxygen supply by red blood cells. Front Physiol. 2013;4:332.

10. Mail J, Mohamed R, Farah N, Aziz AR,Muhamed AMC. The influence of different levels of cardiorespiratory fitness on excercise performance 24 hour post blood donation in maledonors. Mal J Med Health Sci. 2018;14(Supp 1):126-33.

11. Otto JM, O'Doherty AF, Hennis P, Cooper PJ, Grocott M, Snowdon C, et al. Association between preoperative haemoglobin concentration and cardiopulmonary exercise variables: a multicentre study. Perioper Med (Lond). 2013;2:18

12. Jamali NH, Jamali AH, Khand AA, Mahesar H, Arain MI. Factors affecting the body mass index, haemoglobin and serum ferritin level in students. Am J Blood Res. 2017;7(3):18-28.

13. Cairo DARC, Silva LR, Bustani NC, Marques CD. Irondeficiency anemia in adolescents; a literature review. Nutr Hosp. 2014;29(6):1240-9.

14. Ocas-Cordova S, Tapia V, Gonzales GF. Hemoglobin concentration in children at different altitudes in Peru: proposal for [Hb] correction for altitude to diagnose anemia and polycythemia. High Alt Med Biol. 2018;19(4):398-403.

15. Ghosh S, Sinha S, Shivakumar N, Thomas T, Sachdev HS, Kurpad AV. Daily iron requirements in healthy indian children and adolescents. Indian Pediatr. 2019;56(7):551-5. 